\title{
Furin prodomain ppFurin enhances SOCE through TRPC6 activation in
}

\section{breast cancer cells}

\author{
Jose J. López ${ }^{1 \dagger}$, Geraldine Siegfried ${ }^{2 \dagger}$, Carlos Cantonero ${ }^{1}$, Jean Descarpentrie ${ }^{2}$, Tarik Smani ${ }^{3}$, Iker \\ Badiola $^{4}$, Simon Pernot ${ }^{5}$, Serge Evrard ${ }^{5}$, Juan A. Rosado ${ }^{1 \ddagger}$ and Abdel-Majid Khatib ${ }^{2,3 \ddagger}$ \\ $\ddagger,+$ Equal Contribution \\ 1 Department of Physiology, University of Extremadura, Caceres, Spain; jjlopez@unex.es (J.J.L), \\ carloscantonero@unex.es (C.C.), jarosado@unex.es (J.A.R). \\ 2 Univ. Bordeaux, INSERM, LAMC, U1029, F-33600 Pessac, France; geraldine.siegfried@inserm.fr; (G.S) \\ descarpentrie.jean@gmail.com (J.D), majid.khatib@inserm.fr (AM. K) \\ 3 Department of Medical Physiology and Biophysics, University of Seville, Seville 41009, Spain; tasmani@us.es \\ (T.S.) \\ ${ }^{4}$ Department of Cell Biology and Histology, Faculty of Medicine and Nursing, University of the Basque \\ Country, 48940 Leioa, Spain, iker.badiola@gmail.com ( I.B) \\ 5 Bergonié Institute, Bordeaux, France; S.Evrard@bordeaux.unicancer.fr (S.E), s.pernot@bordeaux.unicancer.fr \\ (S.P) \\ * Correspondence: majid.khatib@inserm.fr (AM. K); and jarosado@unex.es (J. A.R);
}

Received: date; Accepted: date; Published: date

\begin{abstract}
:
The intracellular calcium concentration $\left(\left[\mathrm{Ca}^{2+}\right]_{i}\right)$ modulation plays a key role in the regulation of cellular growth and survival in normal cells and failure of $\left[\mathrm{Ca}^{2+}\right]$ i homeostasis is involved in tumor initiation and progression. Here we show that inhibition of Furin by its naturally occurring inhibitor the prodomain ppFurin in the MDA-MB-231 breast cancer cells resulted in enhanced SOCE through TRPC6 activation that associated reduced cells malignant phenotype. Expression of ppFurin in a stable manner in MDA-MB-231 and the melanoma MDA-MB-435 cell lines inhibits Furin activity as assessed by in vitro digestion assays. Accordingly, cell transfection experiments, revealed that the ppFurin-expressing cells are unable to process adequately the PC substrates proVEGF-C and proIGF-1R. Compared to MDA-MB-435 cells, expression of ppFurin in MDA-MB-231 significantly induces $\mathrm{Ca}^{2+}$ entry which is impaired by silencing of TRPC6 expression. Analysis of TRPC6 activation revealed its up-regulated tyrosine phosphorylation in ppFurin-expressing MDA-MB-231 cells. The expression of ppFurin in MDA-MB-231 cells reduced their viability and ability to migrate and enhanced their sensitization to the apoptosis inducer hydrogen peroxide. These findings suggest that Furin inhibition by ppFurin may be a useful strategy to interfere with $\mathrm{Ca}^{2+}$ mobilization leading to breast cancer cells malignant phenotype repression and reduction of their resistance to treatments.
\end{abstract}

Keywords: Furin; ppFurin; Breast cancer; Calcium; SOCE; TRPC6; Viability; Migration.

\section{Introduction}

After lung cancer, breast cancer is the second most common cancer worldwide; and the incidence of this cancer is continually increasing and even though treatment of breast cancer has improved in recent years more than 600,000 people still died from this disease every year [1]. Like various cancers breast cancer directly involves changes in intracellular $\mathrm{Ca}^{2+}$ dynamics $[2,3]$. Such 
variations are frequently associated with intensification of cancer-related processes, including cell proliferation, migration and/or escaping of cell apoptosis [2,3]. In breast cancer cells, the levels of $\mathrm{Ca}^{2+}$ can be increased by the influx of extracellular $\mathrm{Ca}^{2+}$ via the $\mathrm{Ca}^{2+}$ channels in the plasma membrane. In addition, the remodeling of $\mathrm{Ca}^{2+}$ homeostasis can be mediated by changes in the expression of these channels and $\mathrm{Ca}^{2+}$ pumps as well [4]. In many circumstances, changes in $\left[\mathrm{Ca}^{2+}\right]_{i}$ are controlled by intracellular $\mathrm{Ca}^{2+}$ store mobilization and $\mathrm{Ca}^{2+}$ influx through hormones, growth factor receptors activation [2-4]. Interestingly, wide range of these secretory proteins are synthesized as inactive precursors that are converted to their bioactive forms at the general motif $(K / R)-(X) n-(K / R) \downarrow$, where $n=0,2,4$ or 6 by Furin-like enzymes [5-8].

Furin, also known as PCSK3, is a proprotein convertase that belongs to a family of $\mathrm{Ca}^{2+}$-dependent serine peptidases. Synthesized as a precursor protein (preppFurin), this enzyme requires autocleavage in the secretory pathway for its activation $[5,9,10]$. Following the removal of the "pre" signal peptide in the endoplasmic reticulum (ER), the remaining protein is than autocatalytically processed in the secretory pathway to generate the N-terminal ppFurin fragment and mature active Furin. N-terminal ppFurin fragment is associated with the enzyme functions as a potent inhibitor $[5,9,10]$. The presence of a C-terminal membrane binding domain $[5,9,10]$ in the mature Furin allows this enzyme to cycle between the Golgi and plasma membrane and mediate the maturation of a strikingly varied set of proproteins. These include growth factors, receptors and differentiation factors, adhesion molecules and proteases, which have been associated with tumor initiation and different stages of tumor progression, angiogenesis, immune response and metastasis $[5,6,11-14]$. Based on various studies describing the activation of many proteins implicated in neoplasia by Furin, such as growth factors, their receptors, proteases and adhesion molecules, it was hypothesized that this protease may constitute a new potential target for cancer therapy $[5,6,11-13]$. Subsequently, comparative analysis of normal and tumor tissues derived from patients revealed altered expression levels of Furin in various types of cancers including breast cancer $[5,15]$.

In this study, we aimed to characterize $\mathrm{Ca}^{2+}$ changes in response to Furin repression by ppFurin in MDA-MB-231 breast cancer cells, with a focus on investigating the relationship between $\mathrm{Ca}^{2+}$ concentration changes, TRPC6 activation and malignant phenotype repression by ppFurin. Our results indicate that ppFurin mediates $\mathrm{Ca}^{2+}$ influx by means of TRPC6 channels activation that associates with MDA-MB-231 cells viability and migration reduction and enhances sensitization to the apoptotic agent hydrogen peroxide. These studies provide new insights into the consequences of Furin activity on $\mathrm{Ca}^{2+}$ homeostasis in breast cancer cells.

\section{Results}

\subsection{Furin activity is repressed by ppFurin in breast cancer cells}

To investigate the role of Furin in the regulation of $\mathrm{Ca}^{2+}$ mobilization in breast cancer cells, MDA-MB231 were stably transfected with pIRES2-EGFP empty vector (Control) or containing ppFurin cDNA. For comparison, the melanoma cells MDA-MB435 were also transfected with pIRES2-EGFP empty vector (Control) or containing ppFurin. Using an in vitro enzymatic digestion assay $[16,17]$ and the universal proprotein convertases (PCs) substrate: the fluorogenic peptide pERTKR-MCA, revealed that while high PCs activity was detected in Control MDA-MB231 cells, the expression of ppFurin in these cells inhibited PCs enzymatic activity (Figure 1a-1c). Similarly the expression of ppFurin in the melanoma cell line MDA-MB-435, also represses the PCs activity (Figure 1b-1d). Using specific primers for the PCs found in the secretory pathway, namely Furin, PC5, PAEC4 and PC7 real-time PCR confirmed the presence of all these PCs in control MDA-MB-231 and MDA-MB-435 cells. In the presence of ppFurin, the mRNA level of Furin was reduced (Figure 1e-1f). 
a

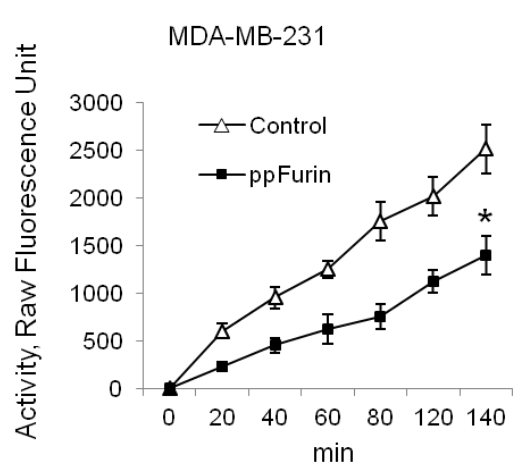

C

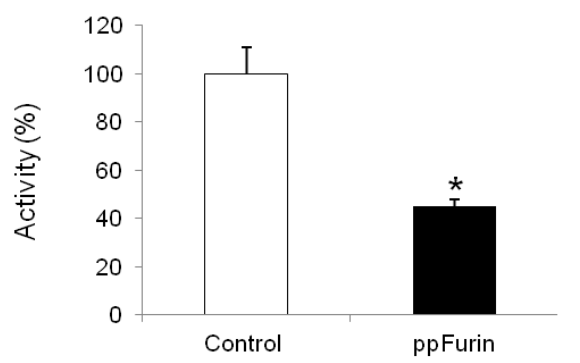

e

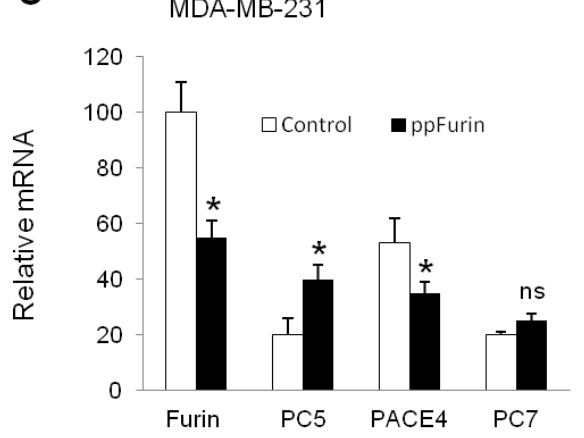

b
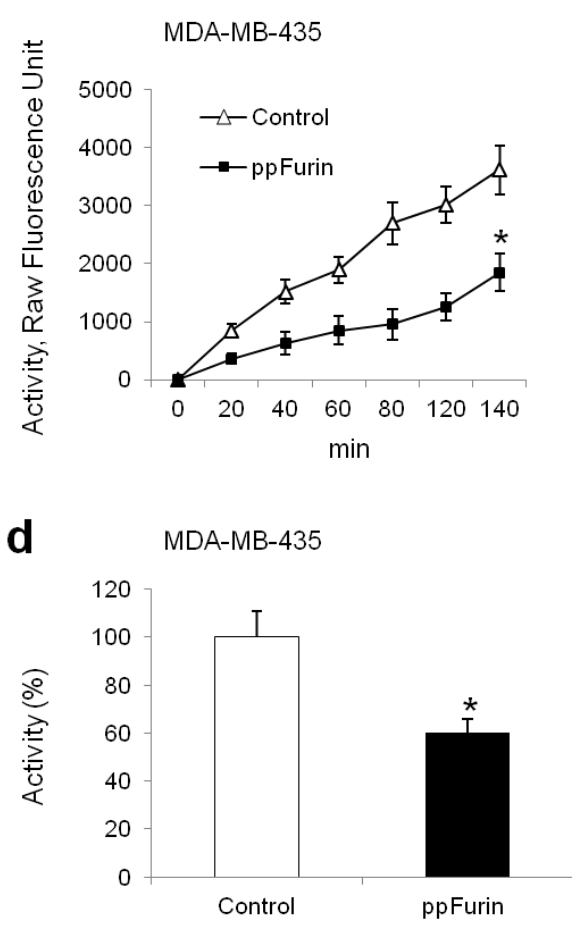

f

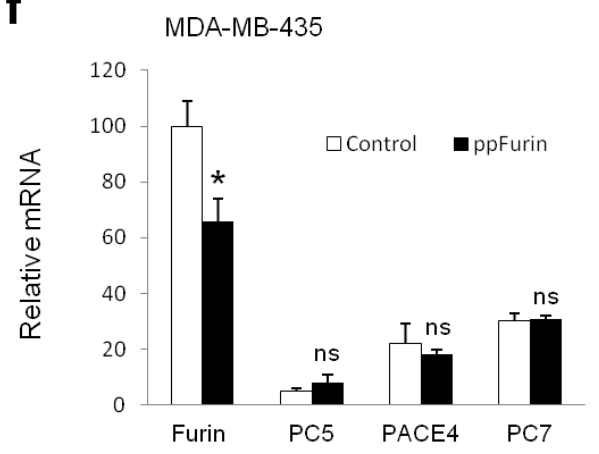

Figure 1. Inhibition of Furin activity by ppFurin in breast MDA-MB-231 and melanoma MDA-MB-435 cell lines. $(\mathbf{a}, \mathbf{b})$ MDA-MB-231 and MDA-MB-435 cells were stably transfected with pIRES2-EGFP empty vector (Control) or pIRES2-EGFP-ppFurin and the PCs activity was evaluated by the measurement of cell lysates ability to digest the universal PCs substrate pERTKR-MCA at the indicated time periods. (c, d) Bar graphs representing PCs activity of MDA-MB-231 and MDA-MB-435 cells at 2 hours of incubation in the absence and presence of ppFurin. (e, f) Real-time PCR analysis of indicted PCs expression in Control and ppFurin-expressing cells. Results are shown in the bar graphs and are expressed as the percentage of enzymatic activity or transcripts relative to controls $(100 \%)$. All values are presented as means \pm SEM of three independent experiments. Statistical significance was assessed by t-test and ${ }^{*}$ represents $\mathrm{p}<0.05$ as compared to the corresponding 103 controls.

To further confirm the effect of ppFurin on the enzymatic activity in MDA-MB-231 and MDA-MB-435 ppFurin expressing cells, we next assessed in these cells their ability to convert the human furin substrate proVEGF-C into the mature VEGF-C form. Immunoblotting analysis revealed that media derived from MDA-MB-231 and MDA-MB-435 cells transfected with a vector encoding proVEGF-C, mostly express the mature form of VEGF-C. Transfection of ppFurin expressing cells with vector encoding proVEGF-C showed reduction of the mature protein and enhanced the accumulation of the unprocessed form of VEGF-C (Figure 2a-2b). Similarly, immunoblotting analysis of the processing of the PCs substrate proIGF-1R revealed that MDA-MB-231 and MDA-MB-435 cell lines express proIGF-1R of which the processing of the $\beta$-subunit was also 
113

114

115

116

117

blocked in MDA-MB-231 and MDA-MB-435 cells in the presence of ppFurin, as evidenced by the accumulation of the precursor form and the reduction of the mature form of IGF-1R. For comparison the processing of proVEGF-C and proIGF-1R was also examined in Control cells and in the presence

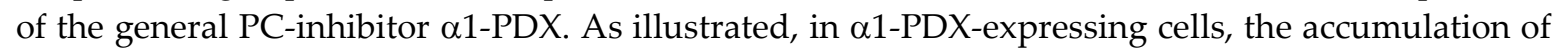
proVEGF-C and proIGF-1R precursor forms was also enhanced (Figure 2).

a

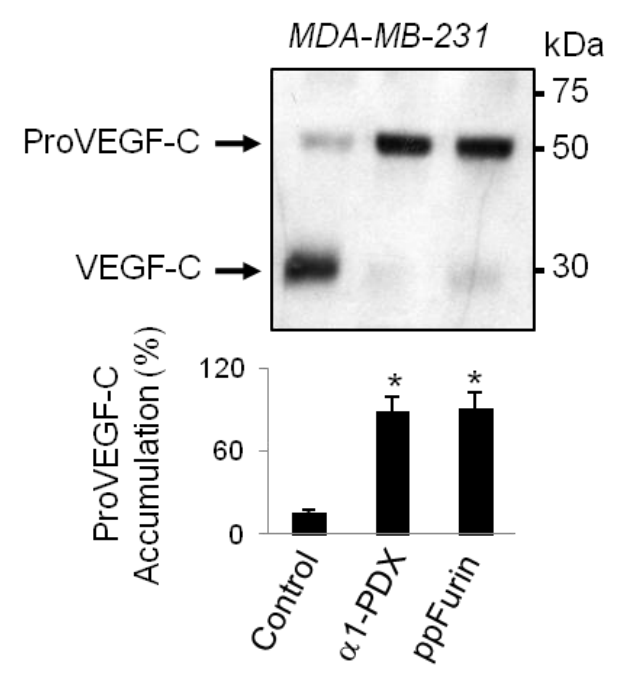

C

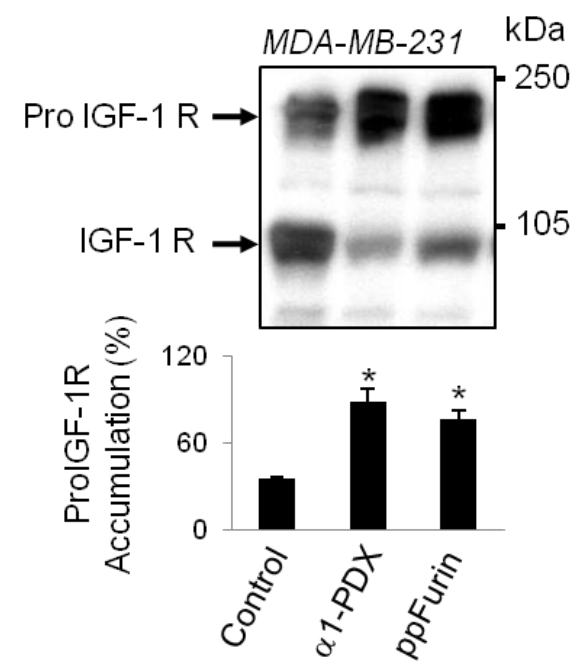

b

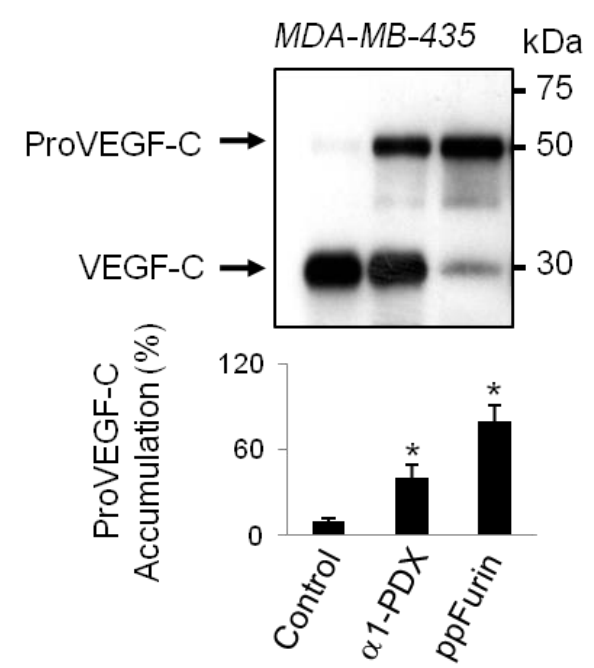

d

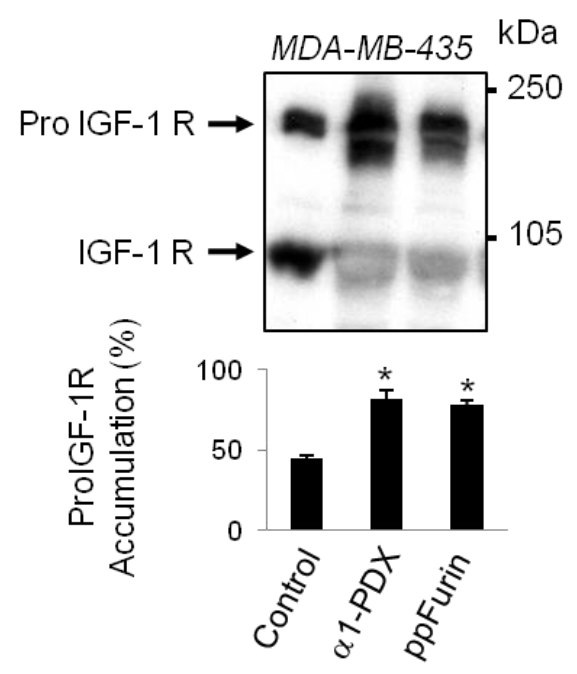

118

Figure 2. Inhibition of proVEGF-C and proIGF-1R by ppFurin in breast MDA-MB-231 and melanoma MDA-MB-435 cell lines. Western blotting for proVEGF-C precursor and its mature form $(\mathbf{a}, \mathbf{b})$ and for proIGF-1R precursor and its mature form $(\mathbf{c}, \mathbf{d})$ expression. Effect of the general PC-inhibitor $\alpha 1-P D X$ on proVEGF-C and proGF-1R cleavage is given for comparison. Bar graphs indicate the percentages of proVEGF-C and proIGF-1R accumulations in the absence and presence of ppFurin or $\alpha 1-P D X$. All values are presented as means \pm SEM of three independent experiments. Statistical significance was assessed by t-test and * represents $\mathrm{p}<0.05$ as compared to the corresponding controls.

\subsection{Regulation of $\mathrm{Ca}^{2+}$ mobilization by ppFurin}

Next, we have investigated the possible effect of ppFurin on $\mathrm{Ca}^{2+}$ mobilization in MDA-MB-231 cells. As depicted in Figure 3a, in cells stably transfected with pIRES2-EGFP empty vector perfused with a $\mathrm{Ca}^{2+}$ free medium, treatment with the SERCA inhibitor TG led to a transient increase in $\left[\mathrm{Ca}^{2+}\right]_{i}$ 
130

131

132

133

134

135

136

137

138

as a consequence of $\mathrm{Ca}^{2+}$ release from the intracellular stores. Subsequent re-addition of $\mathrm{CaCl}_{2}$ to the extracellular medium resulted in a further increase in $\left[\mathrm{Ca}^{2+}\right]_{i}$ indicative of SOCE. Expression of ppFurin significantly enhanced TG-evoked SOCE without having any effect on $\mathrm{Ca}^{2+}$ release from the intracellular stores (Figure 3a). The effect of ppFurin was specific for MDA-MB-231 cells as it did not have any effect on TG-induced $\mathrm{Ca}^{2+}$ mobilization in the melanoma cell line MDA-MB-435 (Figure 3b). Furthermore, we have found that expression of ppFurin in MDA-MB-231 cells leads to transient constitutive $\mathrm{Ca}^{2+}$ entry detected as a rise in $\left[\mathrm{Ca}^{2+}\right]_{i}$ upon re-addition of extracellular $\mathrm{Ca}^{2+}$ in the absence of stimuli, while this effect was absent in MDA-MB-231 and MDA-MB-435 Control cells and MDA-MB-435 stably expressing ppFurin (Figure 4a-d).

a

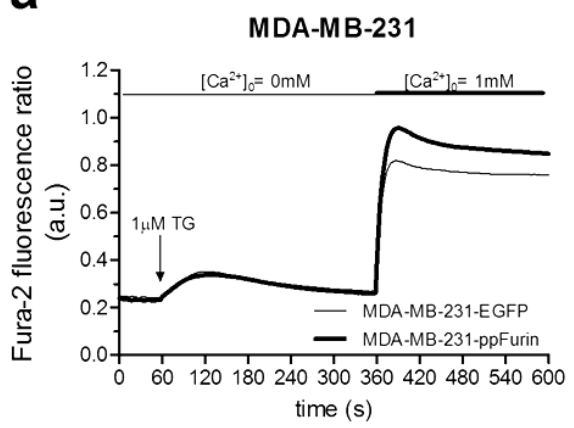

C

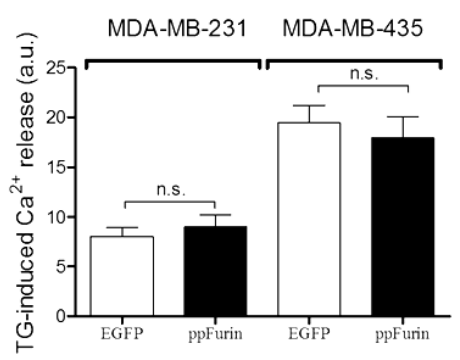

e

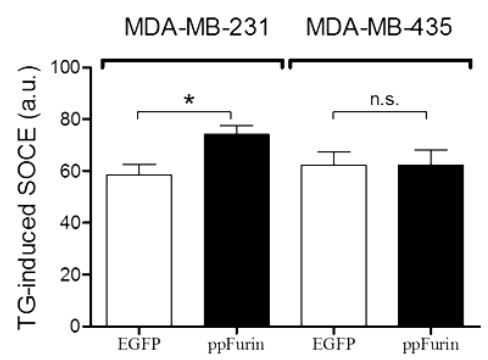

b

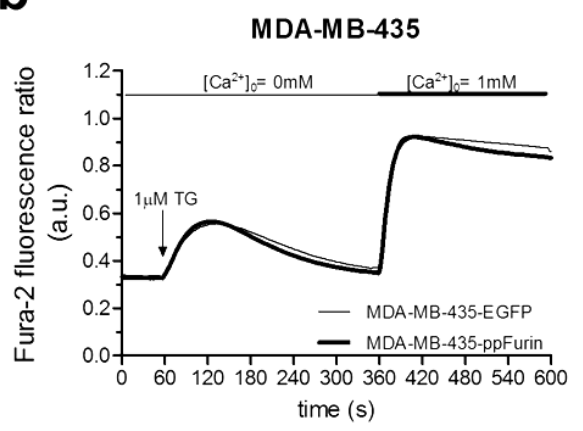

d

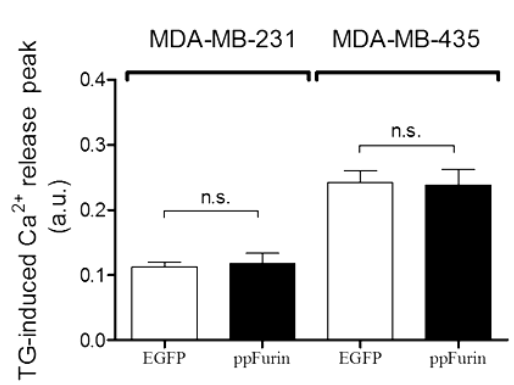

f

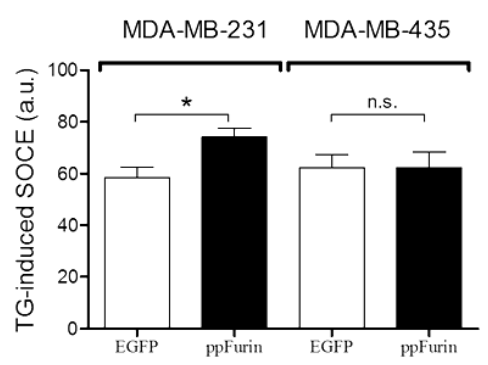

Figure 3. ppFurin enhances SOCE in MDA-MB-231 cells. Control MDA-MB-231 and MDA-MB-435 cells or expressing ppFurin were loaded with fura-2- and perfused with a $\mathrm{Ca}^{2+}$ free medium (100 $\mu \mathrm{M}$ EGTA added) and then stimulated with TG $(1 \mu \mathrm{M})$ followed by reintroduction of external $\mathrm{Ca}^{2+}$ (final concentration $1 \mathrm{mM}$ ) to initiate $\mathrm{Ca}^{2+}$ entry. (a,b) Traces are representative of 40 cells/day/3-5 days. (c-f) Bar graphs represent TG-induced $\mathrm{Ca}^{2+}$ release and SOCE as the area under the curve $(\mathbf{c}, \mathbf{e})$ or the initial peak $\left[\mathrm{Ca}^{2+}\right]_{i}$ elevation above basal $(\mathbf{d}, \mathbf{f})$, expressed as mean \pm SEM. Statistical significance was assessed by Student's $\mathrm{t}$-test and ${ }^{*}$ represents $\mathrm{p}$

TRPC6 is upregulated in MDA-MB-231 cells and play a relevant role in the activation of SOCE in these cells [18]. Hence, we have investigated whether TRPC6 mediates the increase in SOCE as 
151 depicted in Figure 4e-h, TRPC6 expression silencing inhibits constitutive $\mathrm{Ca}^{2+}$ entry in 152 ppFurin-expressing cells, without having any effect in cells expression empty vector. As previously 153 reported [18], attenuation of TRPC6 expression in MDA-MB-231 cells transfected with pIRES2-EGFP 154 empty vector or ppFurin significantly inhibits SOCE with no change in $\mathrm{Ca}^{2+}$ release from the 155 intracellular stores (Figure 5c-h). Interestingly, in cells expressing ppFurin, TRPC6 expression 156 silencing resulted in a greater inhibition of SOCE than in mock-treated cells. As a result, SOCE in 157 ppFurin-expressing and control cells was comparable after TRPC6 knockdown (Figure $5 \mathrm{f}$ and $5 \mathrm{~h}$ ), 158 thus indicating that TRPC6 is responsible for the increased SOCE in ppFurin-expressing cells.

a

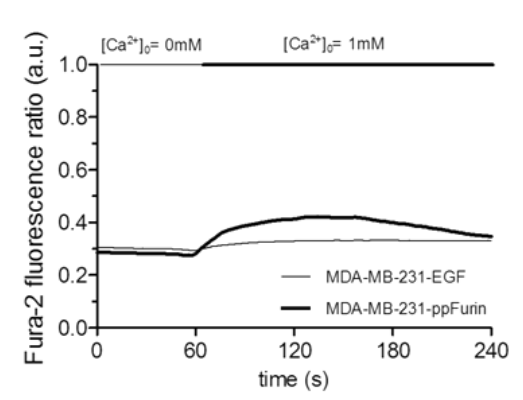

C

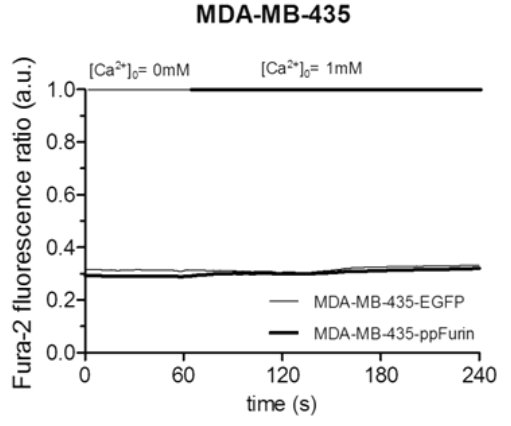

e

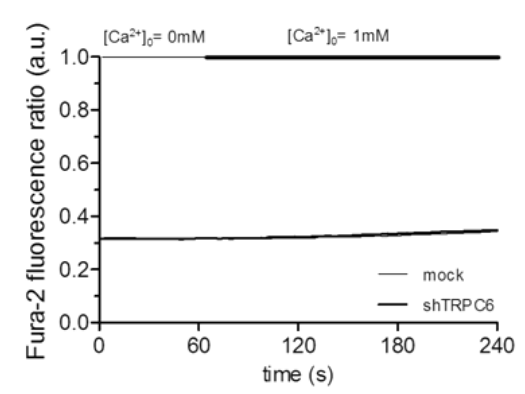

g

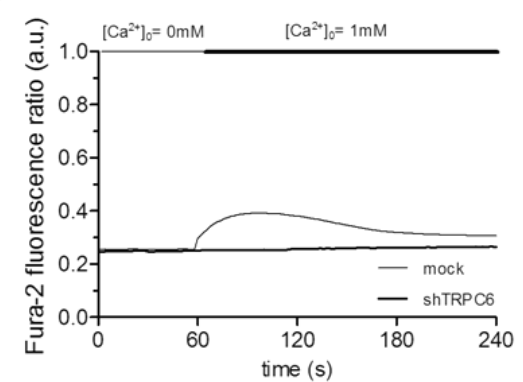

b

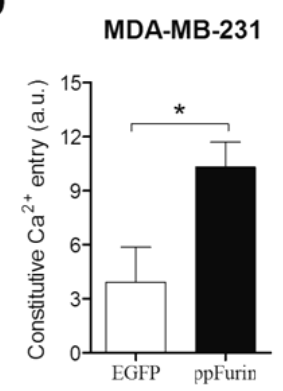

d

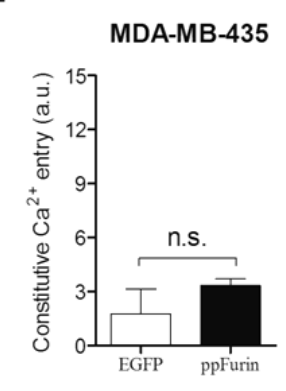

f

MDA-MB-231-EGFP

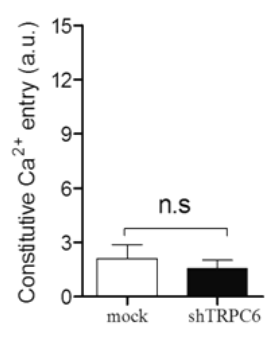

h

MDA-MB-231-ppFurin

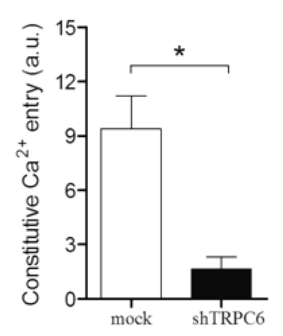


160

161

162

163

164

165

166

167

168

Figure 4. ppFurin induces constitutive $\mathrm{Ca}^{2+}$ entry in MDA-MB-231 cells. (a-d) Control MDA-MB-231 and MDA-MB-435 cells or expressing ppFurin were loaded with fura-2- and perfused with a $\mathrm{Ca}^{2+}$ free medium (100 $\mu \mathrm{M}$ EGTA added) and then were subjected to $\mathrm{Ca}^{2+}$ re-addition to determine the existence of constitutive $\mathrm{Ca}^{2+}$ entry. (e-h) Control MDA-MB-231 and MDA-MB-435 cells or expressing ppFurin were transfected with shTRPC6 or scramble plasmid, as indicated. Forty-eight hours after transfection, cells were with fura-2 and perfused with a $\mathrm{Ca}^{2+}$-free medium $\left(100 \mu \mathrm{M}\right.$ EGTA added) and then were subjected to $\mathrm{Ca}^{2+}$ re-addition to determine the existence of constitutive $\mathrm{Ca}^{2+}$ entry. Traces are representative of 40 cells/day/3-5 days. Bar graphs represent constitutive $\mathrm{Ca}^{2+}$ entry as the area under the curve, expressed as mean $\pm \mathrm{SEM}$. Statistical significance was assessed by Student's t-test and * represents $\mathrm{p}<0.05$ as compared to the corresponding control.
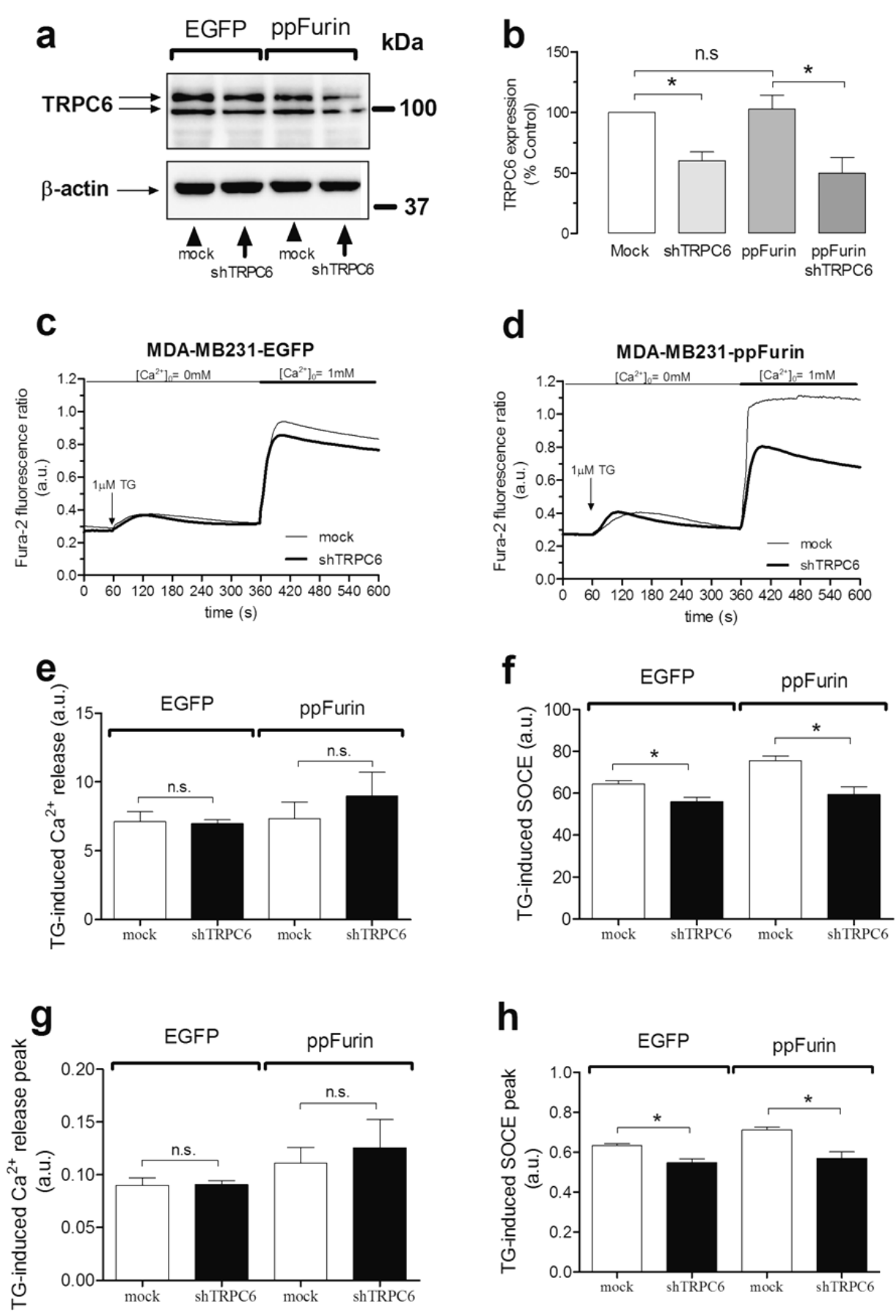

Figure 5. TRPC6 mediates the enhanced SOCE induced by ppFurin in MDA-MB-231 cells. (a) Control MDA-MB-231 cells or the same cells expressing ppFurin were transfected with shTRPC6 or scramble plasmid, as indicated. After $48 \mathrm{~h}$ cells were lysed and subjected to Western blotting using an anti-TRPC6 antibody, 
173

174

175

176

177

178

179

180

181

182

183

184

185

186

187

188

189

190

191

192

193

194

195

196

197

198

199

200

201

202

203

followed by reprobing with anti- $\beta$-actin antibody for protein loading control. (b) Bar graphs represent TRPC6 expression under the different experimental conditions. (c-h) Control MDA-MB-231 cells or expressing ppFurin were loaded with fura- 2 and cells were perfused with a $\mathrm{Ca}^{2+}$-free medium (100 $\mu \mathrm{M}$ EGTA added) and then stimulated with TG $(1 \mu \mathrm{M})$ followed by reintroduction of external $\mathrm{Ca}^{2+}$ (final concentration $1 \mathrm{mM}$ ) to initiate $\mathrm{Ca}^{2+}$ entry. Traces are representative of 40 cells/day/3-5 days. (e-h) Bar graphs represent TG-induced Ca ${ }^{2+}$ release and SOCE as the area under the curve $(\mathbf{e}, \mathbf{g})$ or the initial peak $\left[\mathrm{Ca}^{2+}\right]_{\text {i }}$ elevation above basal $(\mathbf{f}, \mathbf{h})$, expressed as mean \pm SEM. Statistical significance was assessed by Student's t-test and * represents $p<0.05$ as compared to the respective control.

\subsection{Activation of TRPC6 Channels in MDA-MB-231 ppFurin-expressing cells}

Next, we explored the mechanism underlying the activation of TRPC6 by ppFurin. Our results indicate that TRPC6 expression is similar in control and ppFurin-expressing cells (Figure 5a). TRPC6 has been reported to be activated by tyrosine phosphorylation [19], hence, we have explored whether ppFurin is able to induce TRPC6 tyrosine phosphorylation in MDA-MB-231 cells. As depicted in Figure 6, in MDA-MB-231 cells transfected with pIRES2-EGFP empty vector treatment with TG resulted in a significant increase in the phosphotyrosine level of TRPC6. Interestingly, expression of ppFurin in these cells significantly increased TRPC6 tyrosine phosphorylation, and thus activation, under resting conditions and TG was unable to induce further increase in the phosphotyrosine level of the channel (Figure 6). These findings might explain the constitutive Ca ${ }^{2+}$ entry as well as the increase in SOCE induced by ppFurin in MDA-MB-231 cells.
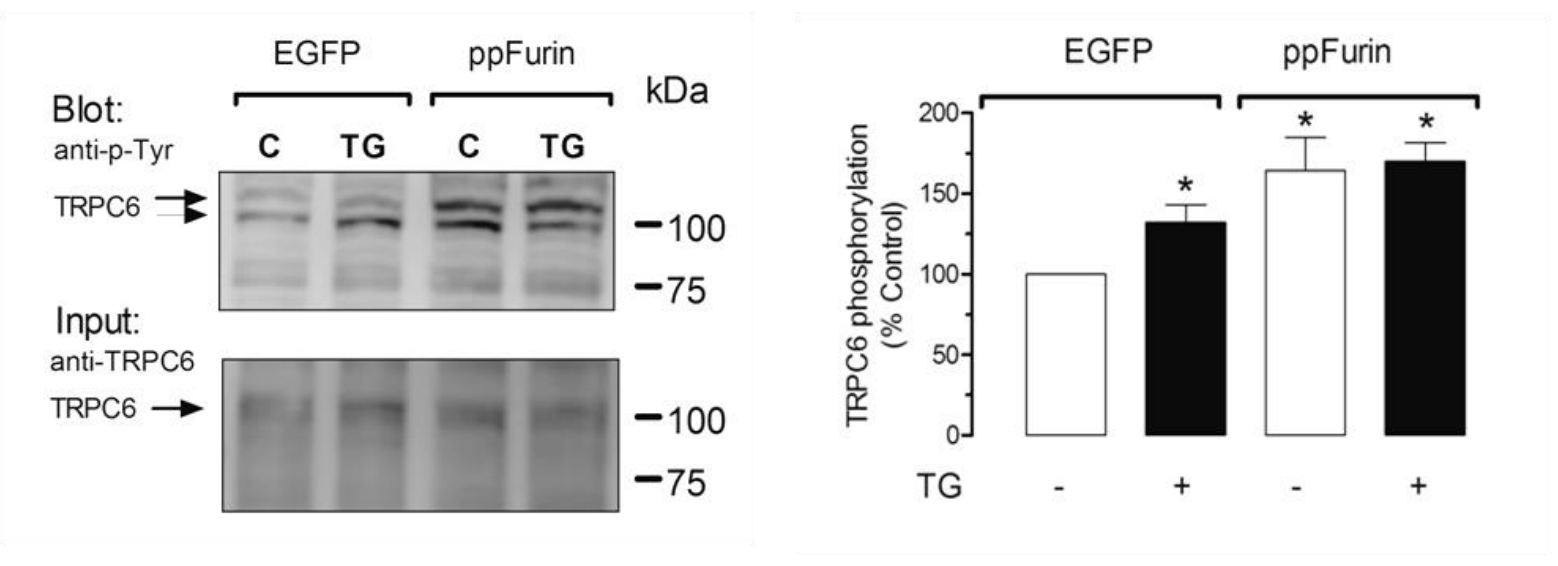

Figure 6. ppFurin induces TRPC6 tyrosine phosphorylation in MDA-MB-231 cells. Control MDA-MB-231 cells or expressing ppFurin were stimulated with $1 \mu \mathrm{M}$ TG for $3 \mathrm{~min}$ or left untreated and lysed. Whole cell lysates were immunoprecipitated (IP) with anti-TRPC6 antibody and immunoprecipitates were subjected to $10 \%$ SDS-PAGE and subsequent Western blotting with specific anti-phosphotyrosine antibody, as indicated. Membranes were reprobed with the antibody used for immunoprecipitation for protein loading control. The panels show results from one experiment representative of five others. Bar graphs represent the quantification of TRPC6 tyrosine phosphorylation in resting and TG-treated cells. Results are presented as percentage of control (cells transfected with pIRES2-EGFP empty vector and not stimulated with TG) and expressed as mean \pm S.E.M. Statistical significance was assessed by one-way analysis of variance combined with the Dunnett post hoc test and * represents $\mathrm{p}<0.05$ as compared to control.

\subsection{Inhibition of MDA-MB-231 malignant phenotype by ppFurin}

Previously induction of TRPC6 was reported to promote the aggressive phenotype of various cancer cells by promoting a sustained elevation of intracellular $\mathrm{Ca}^{2+}$ level, which is critical for cancer cells proliferation and migration [18]. While other studies reported that TRPC6 overactivation 
mediated a significant reduction in breast cancer cells growth and viability [20]. Thereby, we first determined whether the TRPC6 activation in ppFurin-expressing MDA-MB-231 cells was accompanied by alteration in their viability and resistance to the apoptotic agent hydrogen peroxide $\left(\mathrm{H}_{2} \mathrm{O}_{2}\right)$. Thereby, cells were treated for $6 \mathrm{~h}$ with various concentration of $\mathrm{H}_{2} \mathrm{O}_{2}$ and the cytotoxic effect was evaluated using the MTT assay (Figure 7a). As illustrated, $\mathrm{H}_{2} \mathrm{O}_{2}$ inhibited MDA-MB-231 cells viability in a dose-dependent manner that was further enhanced in the presence of ppFurin (Figure 7a). Similarly using cell motility and collagen invasion assays revealed that the expression of ppFurin in these cells delayed MDA-MB-231 monolayer repair following a scratch wound (Figure $7 \mathrm{~b}-\mathrm{c}$ ) and repressed their ability to invade collagen (Figure $7 \mathrm{~d}-\mathrm{e})$, respectively.

\section{a}

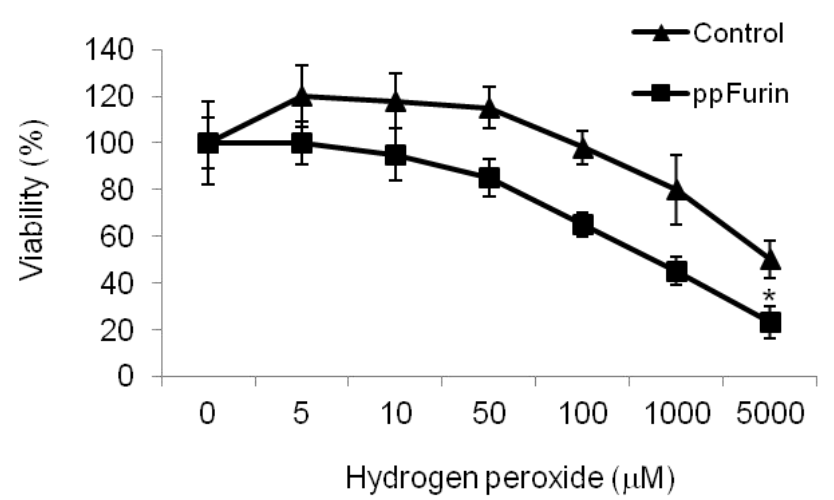

b

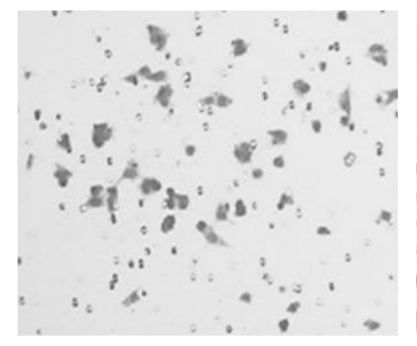

Control

d
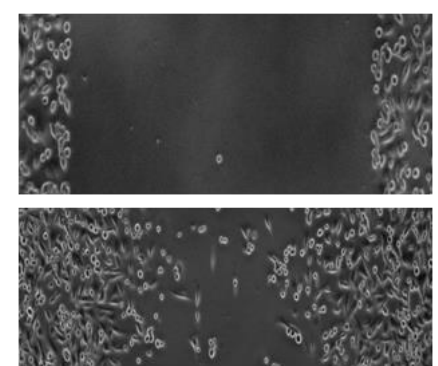

Control

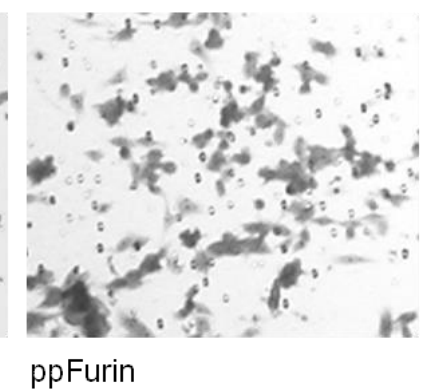

ppFurin

\section{C}

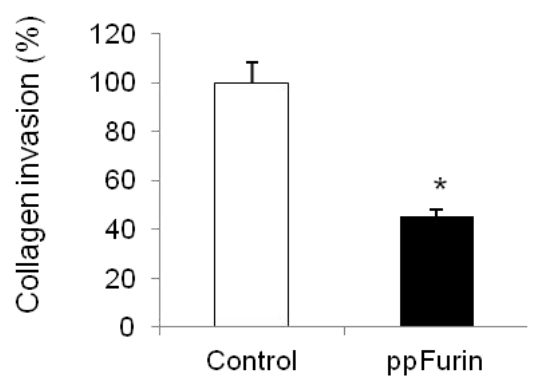

e

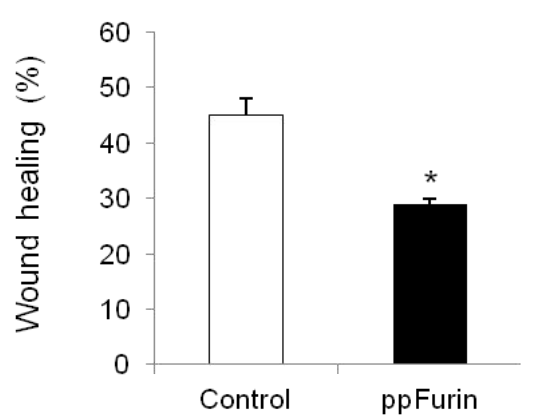

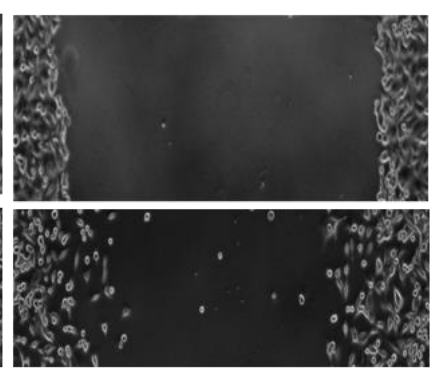

ppFurin
218 Figure 7. ppFurin enhances MDA-MB-231 cells sensitization to hydrogen peroxide $\left(\mathrm{H}_{2} \mathrm{O}_{2}\right)$ and reduces cell invasion and motility. (a) Effect of hydrogen peroxide on Control and ppFurin-expressing MDA-MB-231 cells viability as assessed by MTT assay and calculated with respect to control, which is set as $100 \%$. (b) Control and ppFurin-expressing MDA-MB-231 cells were incubated in a microchemotaxis chamber pre-coated with collagen 
IV for cell invasion assay, as indicated. (c) The results are represented as the percentage of invading cells. (d) Cell motility was analyzed by scratch wound assay. Control and ppFurin-expressing MDA-MB-231 cells were subjected to scratch wounds and imaged after 24 hours ( $n=6 /$ well). (e) Quantification of wound closure after 24 hours of Control MDA-MB-231 cells and the same cells stably expressing ppFurin. All data are representative of 3 experiments and shown as mean \pm S.E.M ( $n=3$ per group). ${ }^{*} \mathrm{P}<0.05$. Student's t test was applied for statistical analysis. $P$ values of $<0.05$ were considered significant.

\section{Discussion}

Proteolytic maturation of protein precursors by furin is involved in various cellular mechanisms directly responsible for the malignant phenotype of a variety of tumors including breast cancers [21-23]. These processes often involve the activation of proteins required for cell proliferation, invasion and signaling pathways that sustain cancer cell growth and viability [21-23]. We have previously reported that inhibition of protein precursors cleavage can affect these processes in different tumor cell types [9-12,14]. In particular, inhibition of the proprotein convertases (PCs) by the exogenous general PCs inhibitor $\alpha 1-P D X$ elicits the repression of the activity of all the PCs found in the secretory pathway leading to the inhibition of a variety of growth factors, receptors and proteases resulting in reduced tumor cells proliferation, invasion and/or survival [9-12,14].

Since $\mathrm{Ca}^{2+}$ signaling and various $\mathrm{Ca}^{2+}$ regulating proteins known to be involved in breast tumor development and progression are substrates and/or downsteam effectors of the ubiquitously expressed PC furin [10,25], we thought that ppFurin [24], its naturally occurring inhibitor, might be involved in the regulation of $\mathrm{Ca}^{2+}$ mobilization in breast cancer cells. By analyzing the effect of stable expression of ppFurin on PCs activity in MDA-MB-231 breast cancer and MDA-MB-435 melanoma cells, we found that ppFurin reduces significantly the in vitro enzymatic activity of PCs. This was confirmed following the analysis of two distinct furin substrates: proVEGF-C and proIGF-1R and found that ppFurin was driving in the two cell lines the cleavage repression of these protein precursors. Further analysis revealed that expression of ppFurin in MDA-MB-231 but not in MDA-MB-435 melanoma cells significantly induces constitutive $\mathrm{Ca}^{2+}$ entry. This $\mathrm{Ca}^{2+}$ mobilization was found to imply TRPC6 activation, since constitutive $\mathrm{Ca}^{2+}$ entry was disturbed following silencing of TRPC6 expression, as assessed by means of shRNA gene knockdown approach.

Targeting altered $\mathrm{Ca}^{2+}$ homeostasis in cancer cells was previously proposed as a potential anti-cancer strategy. This by interfering with the expression and/or the activity of $\mathrm{Ca}^{2+}$-handling proteins. Indeed, the activity of various $\mathrm{Ca}^{2+}$ channels is known to be important in the control of cancer cells growth and survival [4,25]. Specifically, TRPC6 channels are well established to be implicated in cell proliferation and migration [26] and various hypertrophic gene expression and reported to be mediated by NFAT pathway activation in normal [27] and cancer [28] cells. In this aspect, inhibition of TRPC6 expression or activity was suggested to be applied to target breast cancer cell proliferation and migration [26]. In the current studies, we found that TRPC6 phosphorylation was up-regulated in MDA-MB-231 ppFurin-expressing cells while compared to control MDA-MB-231 cells, leading to an increased SOCE and was associated with reduced cell growth and survival. The relevance of TRPC6 hyperactivity in the inhibition of cell growth and induction of apoptosis has been previously demonstrated [29]. Indeed, while TRPC6 activation is known to promote cell proliferation, its overactivation by hyperforin was reported to induce a significant disorder in $\mathrm{Ca}^{2+}$ signaling that affect cell proliferation and induces apoptosis in cancer cells [20,30]. Similarly, extended enhance in $\left[\mathrm{Ca}^{2+}\right]_{i}$ was reported to activate various apoptotic cascades that encouraged the use of drugs able to maintain enhanced $\left[\mathrm{Ca}^{2+}\right]_{i}$ in cancer treatment. These include 
topotecan [31], arsenic trioxide $\left(\mathrm{As}_{2} \mathrm{O}_{3}\right)$ [32] and 5-Fluorouracil (5-FU) [33] all induce intracellular $\mathrm{Ca}^{2+}$ alteration that leads to apoptosis. For example 5-FU that is used for the treatment of various cancers, including breast cancer, involved the elevation of $\left[\mathrm{Ca}^{2+}\right]_{i}$ that activates p53 resulting in the activation of caspases and lately apoptosis $[33,34]$. In addition to cell growth and proliferation, $\mathrm{Ca}^{2+}$ signaling also plays a central regulatory role in migration [35]. We found that TRPC6 hyperactivation in response to ppFurin expression also inhibited MDA-MB-231 cell migration and invasion. Although how TRPC6 hyperactivation affect MDA-MB 231 cells motility, is quite unclear, the role of TRPC6 in the regulation of actin cytoskeleton system activity may be the major contributing factor. Indeed, TRPC6-mediated $\mathrm{Ca}^{2+}$ influx was reported to be directly associated with actin cytoskeleton that is responsible for the regulation of cell morphology, cell adhesion, and motility [35]. While the TRPC6-mediated $\mathrm{Ca}^{2+}$ entry was found to contribute to migration and invasion, the gain-of-function mutation of TRPC6 found in several podocytes leads to focal and segmental glomerulosclerosis (FSGS), a leading cause of glomerulonephritis and chronic kidney disease [36,37] and proteinuria [38] due to alteration of actin organization and subsequently cell migration repression. In addition, exaggerated $\mathrm{Ca}^{2+}$ signaling mediated by these TRPC 6 mutations was also found to cause apoptosis [37].

An increasing number of studies have identified a wide range of protein precursors in breast cancer cells of which the cleavage and activity are inhibited by furin repression $[21,23,24,39,40]$. These studies highlight the important role for the cleavage of these protein precurssors in breast cancer development and progression and reveals that their cleavage inhbition results in tumor cells proliferation, invasion and survival inhibition. However, further investigations are needed to explore the effect of specific protein precursor cleavage inhibition on TRPC6-mediated Ca2+ entry.

\section{Materials and Methods}

\subsection{Materials and reagents}

Fura-2 acetoxymethyl ester (fura-2/AM) was from Molecular Probes (Leiden, The Netherlands). Thapsigargin (TG) was from Sigma-Aldrich (Madrid, Spain). Rabbit polyclonal anti-TRPC6 antibody (catalog number: TA328771, corresponding to amino acid residues 573-586 of rat TRPC6, 2nd extracellular loop) was from Origene (Rockville, MD, USA). The anti-Insulin-like growth factor I receptor (IGF-1R) and anti-Vascular endothelial growth factor C (VEGF-C) were from Santa Cruz. Mouse-monoclonal anti-phosphotyrosine antibody (catalog number: 05-321) was from Millipore (Temecula, CA, USA). All other reagents were of analytical grade.

\subsection{Cell culture and Transfections.}

The human breast cancer MDA-MB-231 and the melanoma MDA-MB 435 cell lines were stably transfected with pIRES2-enhanced green fluorescent protein (EGFP) empty vector or the same vector expressing the ppFurin cDNA. In other experiments, cancer MDA-MB-231 and the melanoma MDA-MB 435 cell lines were transiently transfected with pcDNA3-zeo-Flag.cm5 empty vector or the same vector containing wild-type VEGF-C. Transfections were carried out using the Effectene transfection reagent (Qiagen) according to manufacturer's instructions and stably ppFurin-expressing cells were selected using G418 resistance, as previously described [41,42]. Cells were grown in DMEM supplemented with 10\% FCS, 100 units $/ \mathrm{ml}$ penicillin, and $100 \mathrm{mg} / \mathrm{ml}$ streptomycin. 
Total RNA extraction was performed using the Macherey-Nagel RNA isolation kit that includs DNase treatment (Qiagen), according to the manufacturer's instructions. The RNA was reverse transcribed using the high capacity cDNA reverse transcription kit (Applied Biosystems, Courtaboeuf, France) and used for real time PCR in the presence of specific primers and Power SYBR Green PCR Master Mix (Applied Biosystems), as previously described [7,9]. The qPCR data were acquired with the StepOnePlusTM Real-Time PCR System (Applied Biosystems, Courtaboeuf, France). The expression levels were normalized to human GAPDH.

\subsection{Immunoprecipitation and Western blotting}

Immunoprecipitation and Western blotting were performed as described previously [43]. Briefly, $500 \mu \mathrm{L}$ aliquots of cell suspension $(18 \times 106$ cell $/ \mathrm{mL})$ were lysed with an equal volume of ice-cold $2 \times \mathrm{NP}-40$ buffer, containing $274 \mathrm{mM} \mathrm{NaCl}, 40 \mathrm{mM}$ Tris, $4 \mathrm{mM}$ EDTA, 20\% glycerol, 2\% nonidet P-40, 2 mM Na $\mathrm{mO}_{4}$ and complete EDTA-free protease inhibitor tablets. Samples of cell lysates $(1 \mathrm{~mL})$ were immunoprecipitated by incubation with $2.5 \mu \mathrm{g}$ of anti-TRPC6 and $50 \mu \mathrm{L}$ of protein A-agarose overnight at $4{ }^{\circ} \mathrm{C}$ on a rotary platform. The immunoprecipitates were resolved by $10 \%$ SDS-PAGE and separated proteins were electrophoreticcally transferred onto nitrocellulose membranes for subsequent probing. Blots were incubated for $3 \mathrm{~h}$ at room temperature with $10 \%$ $(\mathrm{w} / \mathrm{v})$ BSA in tris-buffered saline with $0.1 \%$ Tween 20 (TBST) to block residual protein binding sites. Immunodetection of phosphotyrosine and TRPC6 were achieved by incubation overnight with anti-phosphotyrosine antibody diluted 1:500 in TBST and overnight with anti-TRPC6 antibody diluted in 1:500 in TBST. The primary antibody was removed and blots were washed three times for 10 min each with TBST. Following, Primary antibodies were detected by incubation for $1 \mathrm{~h}$ with horseradish peroxidase-conjugated goat anti-mouse IgG antibody or horseradish peroxidase-conjugated goat anti-rabbit IgG antibody diluted 1:10000 in TBST and then exposed to enhanced chemiluminiscence reagents for $5 \mathrm{~min}$. IGF-1R and VEGF-C cleavage detection by Western blotting analysis was performed as previously described $[9,17]$. The density of bands was measured using C-DiGit Chemiluminescent Western Blot Scanner and ImageJ software (NIH, U.S.A.). Data were normalized to the amount of protein recovered by the antibody used for the immunoprecipitation.

\subsection{Determination of cytosolic free-Ca ${ }^{2+}$ concentration}

Cells were loaded with fura-2 by incubation with $2 \mu \mathrm{M}$ fura $2 / \mathrm{AM}$ for $30 \mathrm{~min}$ at $37{ }^{\circ} \mathrm{C}$. Coverslips with cultured cells were mounted on a perfusion chamber and placed on the stage of an epifluorescence inverted microscope (Nikon Eclipse Ti2, Amsterdam, The Netherlands) with image acquisition and analysis software for videomicroscopy (NIS-Elements Imaging Software, Nikon). Cells were superfused with HEPES-buffered saline (HBS) containing (in mM): $125 \mathrm{NaCl}, 5 \mathrm{KCl}, 1$ $\mathrm{MgCl}$, 5 glucose, 25 HEPES, and $\mathrm{pH} 7.4$, supplemented with $0.1 \%(\mathrm{w} / \mathrm{v})$ BSA, and were alternatively excited with light from a xenon lamp passed through a high-speed monochromator (Optoscan ELE 450, Cairn Research, Faversham, UK) at 340/380 nm. Fluorescence emission at $505 \mathrm{~nm}$ was detected using a sCMOS camera (Zyla 4.2, Andor, Belfast, UK) and recorded using NIS-Elements AR software (Nikon, Amsterdam, The Netherlands). Fluorescence ratio (F340/F380) was calculated pixel by pixel [44]. TG-evoked Ca2+ release and SOCE were measured as the integral of the rise in the fura- 2 fluorescence ratio for $2 \frac{1}{2} 2 \mathrm{~min}$ after the addition of TG or $\mathrm{Ca}^{2+}$, respectively.

\subsection{Cell Viability Assay}

The cell viability was evaluated using the MTT assay, as previously described [45]. Control and MDA-MB-231 ppFurin cells were plated in 96-well microtiter plates respectively at a density of $(1 \times$ $104 / \mathrm{ml}$ ) cells/well. Next day, the cells were treated with various concentration of $\mathrm{H}_{2} \mathrm{O}_{2}$ for $6 \mathrm{~h}$ and were immersed with MTT solution $(0.5 \mathrm{mg} / \mathrm{mL})$ for $3 \mathrm{~h}$ at $37^{\circ} \mathrm{C}$. Then absorbance was measured at $570 \mathrm{~nm}$ using ELISA plate reader. The viability was calculated with respect to control, which is set as $100 \%$. 


\subsection{Cell invasion assay}

The in vitro invasion activity of control and MDA-MB-231 ppFurin-expressing cells was performed using 24-well microchemotaxis chambers precoated with $7.5 \mu \mathrm{g}$ collagen type IV (Becton Dickinson Labware), as previously described $[\mathbf{1 7}, \mathbf{2 1}]$. Tumor cells $\left(1 \times 10^{5} / \mathrm{ml}\right)$ were resuspended in serum-free media and were loaded into the upper chamber of Transwells. Cells were incubated at $37^{\circ} \mathrm{C}$ for $24 \mathrm{~h}$ and invasion across collagen layer was initiated by adding $10 \%$ FBS (chemoattractant) to the lower chamber. Cells detected in each well were counted and the results were represented as (number of migrated cells/number of total cells) $\times 100 \%$.

\subsection{Wound-healing assay}

The wound-healing assay was conducted as previously reported [39]. Briefly, control and MDA-MB-231 ppFurin-expressing cells were seeded into 6-well plate at $5 \times 105$ /well and grown in growth media until $90-100 \%$ confluency. A cell-free area (wound) within the cell monolayer was constructed using a sterile micropipette tip. Healing of the wound was observed after $24 \mathrm{~h}$ by a light microscopy and analyzed using Image J software. The area that remained clear of cells after this period was quantified and compared with the area of the wound at time 0.

\subsection{Statistical analysis}

All data are presented as \pm standard error of mean (SEM) unless specifically mentioned. Student's $t$ test or one-way analysis of variance combined with the Dunnett post hoc test were applied for statistical analysis, as appropriate. P values of $<0.05$ were considered significant.

\section{Conclusions}

Our work shows that expression of ppFurin, a naturally occurring inhibitor of the convertase Furin mediates an activation of TRPC6 that induces enhanced $\mathrm{Ca}^{2+}$ influx in breast cancer cells, driving their reduced viability and migration and their enhanced sensitization to the apoptotic agent hydrogen peroxide. Thus, interfering with furin activity-mediated $\mathrm{Ca}^{2+}$ mobilization and TRPC6 activation represent a potential strategy controlling malignant phenotype and resistance to therapy in breast cancer cells. Prospect studies based on our conclusion will validate the efficacy of overactivation of TRPC6 in breast cancer repression using in vivo models.

\section{Author Contributions:}

Conceptualization, J.A.R., G.S., S.E., and AM. K.; methodology, J.J.L.,G.S., C.C., S.P., J.D., I.B., and T.S.; investigation, J.A.R., and AM.K.; Funding acquisition, J.A.R., G.S., S.E., and AM. K.; writing-original draft preparation, - review and editing, J.A.R., G.S., S.E., and AM.K.; project administration, J.A.R., and AM.K. All authors have read and agreed to the published version of the manuscript.

\section{Funding:}

This research was funded by SIRIC-Brio, La Ligue Contre le Cancer and Region Nouvelle Aquitaine to AMK and by MICINN (Grants BFU2016-74932-C2 and PID2019-104084GB-C21 and C22) and Junta de Extremadura-Fondo Europeo de Desarrollo Regional (FEDER; Grants IB16046 and GR18061) to JAR and TS. J.J.L. is supported by a contract from Junta de Extremadura (TA18011). C.C. is supported by a contract from Junta de Extremadura- FEDER.

\section{Conflicts of Interest:}

The authors declare no conflict of interest.

\section{References}


1. Momenimovahed, Z.; Salehiniya, H. Epidemiological characteristics of and risk factors for breast cancer in the world. Breast Cancer (Dove Med Press) 2019, 11, 151-164, doi:10.2147/BCTT.S176070.

2. Prevarskaya, N.; Ouadid-Ahidouch, H.; Skryma, R.; Shuba, Y. Remodelling of Ca2+ transport in cancer: how it contributes to cancer hallmarks? Philos Trans $R$ Soc Lond B Biol Sci 2014, 369, doi:10.1098/rstb.2013.0097.

3. Azimi, I.; Roberts-Thomson, S.J.; Monteith, G.R. Calcium influx pathways in breast cancer: opportunities for pharmacological intervention. Br J Pharmacol 2014, 171, 945-960, doi:10.1111/bph.12486.

4. Stewart, T.A.; Yapa, K.T.D.S.; Monteith, G.R. Altered calcium signaling in cancer cells. Biochimica et Biophysica Acta (BBA) - Biomembranes 2015, 1848, 2502-2511, doi:10.1016/j.bbamem.2014.08.016.

5. Siegfried, G.; Descarpentrie, J.; Evrard, S.; Khatib, A.-M. Proprotein convertases: Key players in inflammation-related malignancies and metastasis. Cancer Lett. 2020, 473, 50-61, doi:10.1016/j.canlet.2019.12.027.

6. Sfaxi, F.; Scamuffa, N.; Lalou, C.; Ma, J.; Metrakos, P.; Siegfried, G.; Ragg, H.; Bikfalvi, A.; Calvo, F.; Khatib, A.-M. Repression of liver colorectal metastasis by the serpin Spn4A a naturally occurring inhibitor of the constitutive secretory proprotein convertases. Oncotarget 2014, 5, 4195-4210, doi:10.18632/oncotarget.1966.

7. Scamuffa, N.; Basak, A.; Lalou, C.; Wargnier, A.; Marcinkiewicz, J.; Siegfried, G.; Chrétien, M.; Calvo, F.; Seidah, N.G.; Khatib, A.-M. Regulation of prohepcidin processing and activity by the subtilisin-like proprotein convertases Furin, PC5, PACE4 and PC7. Gut 2008, 57, 1573-1582, doi:10.1136/gut.2007.141812.

8. Adam*, F.; Khatib*, A.-M.; Lopez, J.J.; Vatier, C.; Turpin, S.; Muscat, A.; Soulet, F.; Aries, A.; Jardin, I.; Bobe, R.; et al. Apelin: an antithrombotic factor that inhibits platelet function. Blood 2016, 127, 908-920, doi:10.1182/blood-2014-05-578781 * equal contribution.

9. Scamuffa, N.; Sfaxi, F.; Ma, J.; Lalou, C.; Seidah, N.; Calvo, F.; Khatib, A.-M. Prodomain of the proprotein convertase subtilisin/kexin Furin (ppFurin) protects from tumor progression and metastasis. Carcinogenesis 2014, 35, 528-536, doi:10.1093/carcin/bgt345.

10. Lahlil, R.; Calvo, F.; Khatib, A.-M. The potential anti-tumorigenic and anti-metastatic side of the proprotein convertases inhibitors. Recent Pat Anticancer Drug Discov 2009, 4, 83-91, doi:10.2174/157489209787002470.

11. Basak, A.; Khatib, A.-M.; Mohottalage, D.; Basak, S.; Kolajova, M.; Bag, S.S.; Basak, A. A novel enediynyl peptide inhibitor of furin that blocks processing of proPDGF-A, B and proVEGF-C. PLoS ONE 2009, 4, e7700, doi:10.1371/journal.pone.0007700.

12. He, Z.; Thorrez, L.; Siegfried, G.; Meulemans, S.; Evrard, S.; Tejpar, S.; Khatib*, A.-M.; Creemers*, J.W.M. The proprotein convertase furin is a pro-oncogenic driver in KRAS and BRAF driven colorectal cancer. Oncogene 2020, 39, 3571-3587. *Equal contribution, doi:10.1038/s41388-020-1238-z.

13. Creemers, J.W.M.; Khatib, A.-M. Knock-out mouse models of proprotein convertases: unique functions or redundancy? Front. Biosci. 2008, 13, 4960-4971, doi:10.2741/3055.

14. Tomé, M.; Pappalardo, A.; Soulet, F.; López, J.J.; Olaizola, J.; Leger, Y.; Dubreuil, M.; Mouchard, A.; Fessart, D.; Delom, F.; et al. Inactivation of Proprotein Convertases in T Cells Inhibits PD-1 Expression and Creates a Favorable Immune Microenvironment in Colorectal Cancer. Cancer Res. 2019, 79, 5008-5021, doi:10.1158/0008-5472.CAN-19-0086.

15. Khatib, A.-M.; Siegfried, G.; Chrétien, M.; Metrakos, P.; Seidah, N.G. Proprotein Convertases in Tumor Progression and Malignancy. Am J Pathol 2002, 160, 1921-1935.

16. Ma, J.; Evrard, S.; Badiola, I.; Siegfried, G.; Khatib, A.-M. Regulation of the proprotein convertases expression and activity during regenerative angiogenesis: Role of hypoxia-inducible factor (HIF). Eur. J. Cell Biol. 2017, 96, 457-468, doi:10.1016/j.ejcb.2017.06.001. 
17. Lalou, C.; Scamuffa, N.; Mourah, S.; Plassa, F.; Podgorniak, M.-P.; Soufir, N.; Dumaz, N.; Calvo, F.; Basset-Seguin, N.; Khatib, A.-M. Inhibition of the proprotein convertases represses the invasiveness of human primary melanoma cells with altered p53, CDKN2A and N-Ras genes. PLoS ONE 2010, 5, e9992, doi:10.1371/journal.pone.0009992.

18. Jardin, I.; Diez-Bello, R.; Lopez, J.J.; Redondo, P.C.; Salido, G.M.; Smani, T.; Rosado, J.A. TRPC6 Channels Are Required for Proliferation, Migration and Invasion of Breast Cancer Cell Lines by Modulation of Orai1 and Orai3 Surface Exposure. Cancers (Basel) 2018, 10, doi:10.3390/cancers10090331.

19. Hisatsune, C.; Kuroda, Y.; Nakamura, K.; Inoue, T.; Nakamura, T.; Michikawa, T.; Mizutani, A.; Mikoshiba, K. Regulation of TRPC6 channel activity by tyrosine phosphorylation. J. Biol. Chem. 2004, 279, 18887-18894, doi:10.1074/jbc.M311274200.

20. Aydar, E.; Yeo, S.; Djamgoz, M.; Palmer, C. Abnormal expression, localization and interaction of canonical transient receptor potential ion channels in human breast cancer cell lines and tissues: a potential target for breast cancer diagnosis and therapy. Cancer Cell Int 2009, 9, 23, doi:10.1186/1475-2867-9-23.

21. He, Z.; Khatib, A.-M.; Creemers, J.W.M. Loss of the proprotein convertase Furin in T cells represses mammary tumorigenesis in oncogene-driven triple negative breast cancer. Cancer Lett. 2020, 484, 40-49, doi:10.1016/j.canlet.2020.05.001.

22. Khatib, A.-M.; Siegfried, G.; Chrétien, M.; Metrakos, P.; Seidah, N.G. Proprotein convertases in tumor progression and malignancy: novel targets in cancer therapy. Am. J. Pathol. 2002, 160, 1921-1935, doi:10.1016/S0002-9440(10)61140-6.

23. Siegfried, G.; Descarpentrie, J.; Evrard, S.; Khatib, A.-M. Proprotein convertases: Key players in inflammation-related malignancies and metastasis. Cancer Lett. 2020, 473, 50-61, doi:10.1016/j.canlet.2019.12.027.

24. Thomas, G. Furin at the cutting edge: from protein traffic to embryogenesis and disease. Nat. Rev. Mol. Cell Biol. 2002, 3, 753-766, doi:10.1038/nrm934.

25. Leverrier-Penna, S.; Destaing, O.; Penna, A. Insights and perspectives on calcium channel functions in the cockpit of cancerous space invaders. Cell Calcium 2020, 90, 102251, doi:10.1016/j.ceca.2020.102251.

26. Jardin, I.; Diez-Bello, R.; Lopez, J.J.; Redondo, P.C.; Salido, G.M.; Smani, T.; Rosado, J.A. TRPC6 Channels Are Required for Proliferation, Migration and Invasion of Breast Cancer Cell Lines by Modulation of Orai1 and Orai3 Surface Exposure. Cancers (Basel) 2018, 10, doi:10.3390/cancers10090331.

27. Kuwahara, K.; Wang, Y.; McAnally, J.; Richardson, J.A.; Bassel-Duby, R.; Hill, J.A.; Olson, E.N. TRPC6 fulfills a calcineurin signaling circuit during pathologic cardiac remodeling. J. Clin. Invest. 2006, 116, 3114-3126, doi:10.1172/JCI27702.

28. Kim, J.-H.; Hwang, K.-H.; Eom, M.; Kim, M.; Park, E.Y.; Jeong, Y.; Park, K.-S.; Cha, S.-K. WNK1 promotes renal tumor progression by activating TRPC6-NFAT pathway. FASEB J. 2019, 33, 8588-8599, doi:10.1096/fj.201802019RR.

29. Aydar, E.; Yeo, S.; Djamgoz, M.; Palmer, C. Abnormal expression, localization and interaction of canonical transient receptor potential ion channels in human breast cancer cell lines and tissues: a potential target for breast cancer diagnosis and therapy. Cancer Cell International 2009, 9, 23, doi:10.1186/1475-2867-9-23.

30. Donà, M.; Dell'Aica, I.; Pezzato, E.; Sartor, L.; Calabrese, F.; Della Barbera, M.; Donella-Deana, A.; Appendino, G.; Borsarini, A.; Caniato, R.; et al. Hyperforin inhibits cancer invasion and metastasis. Cancer Res. 2004, 64, 6225-6232, doi:10.1158/0008-5472.CAN-04-0280. 
31. Oberhoff, C.; Kieback, D.G.; Würstlein, R.; Deertz, H.; Sehouli, J.; van Soest, C.; Hilfrich, J.; Mesrogli, M.; von Minckwitz, G.; Staab, H.J.; et al. Topotecan chemotherapy in patients with breast cancer and brain metastases: results of a pilot study. Onkologie 2001, 24, 256-260, doi:10.1159/000055088.

32. Ahn, R.W.; Chen, F.; Chen, H.; Stern, S.T.; Clogston, J.D.; Patri, A.K.; Raja, M.R.; Swindell, E.P.; Parimi, V.; Cryns, V.L.; et al. A Novel Nanoparticulate Formulation of Arsenic Trioxide with Enhanced Therapeutic Efficacy in a Murine Model of Breast Cancer. Clin Cancer Res 2010, 16, 3607-3617, doi:10.1158/1078-0432.CCR-10-0068.

33. Longley, D.B.; Harkin, D.P.; Johnston, P.G. 5-fluorouracil: mechanisms of action and clinical strategies. Nat. Rev. Cancer 2003, 3, 330-338, doi:10.1038/nrc1074.

34. Petak, I.; Tillman, D.M.; Houghton, J.A. p53 Dependence of Fas Induction and Acute Apoptosis in Response to 5-Fluorouracil-Leucovorin in Human Colon Carcinoma Cell Lines. Clin Cancer Res 2000, 6, $4432-4441$.

35. Singh, I.; Knezevic, N.; Ahmmed, G.U.; Kini, V.; Malik, A.B.; Mehta, D. Gaq-TRPC6-mediated Ca2+ Entry Induces RhoA Activation and Resultant Endothelial Cell Shape Change in Response to Thrombin. J. Biol. Chem. 2007, 282, 7833-7843, doi:10.1074/jbc.M608288200.

36. Winn, M.P.; Conlon, P.J.; Lynn, K.L.; Farrington, M.K.; Creazzo, T.; Hawkins, A.F.; Daskalakis, N.; Kwan, S.Y.; Ebersviller, S.; Burchette, J.L.; et al. A Mutation in the TRPC6 Cation Channel Causes Familial Focal Segmental Glomerulosclerosis. Science 2005, 308, 1801-1804, doi:10.1126/science.1106215.

37. Reiser, J.; Polu, K.R.; Möller, C.C.; Kenlan, P.; Altintas, M.M.; Wei, C.; Faul, C.; Herbert, S.; Villegas, I.; Avila-Casado, C.; et al. TRPC6 is a glomerular slit diaphragm-associated channel required for normal renal function. Nat Genet 2005, 37, 739-744, doi:10.1038/ng1592.

38. Wang, Q.; Tian, X.; Wang, Y.; Wang, Y.; Li, J.; Zhao, T.; Li, P. Role of Transient Receptor Potential Canonical Channel 6 (TRPC6) in Diabetic Kidney Disease by Regulating Podocyte Actin Cytoskeleton Rearrangement Available online: https://www.hindawi.com/journals/jdr/2020/6897390/ (accessed on Aug 11, 2020).

39. Soulet, F.; Bodineau, C.; Hooks, K.B.; Descarpentrie, J.; Alves, I.; Dubreuil, M.; Mouchard, A.; Eugenie, M.; Hoepffner, J.-L.; López, J.J.; et al. ELA/APELA precursor cleaved by furin displays tumor suppressor function in renal cell carcinoma through mTORC1 activation. JCI Insight 2020, 5, doi:10.1172/jci.insight.129070.

40. He, Z.; Thorrez, L.; Siegfried, G.; Meulemans, S.; Evrard, S.; Tejpar, S.; Khatib, A.-M.; Creemers*, J.W.M. Differential Gene expression of furin knockout (KO) DLD1, HCA7 and HT29 colorectal cancer cells. GEO Accession viewer Available online: https://www.ncbi.nlm.nih.gov/geo/query/acc.cgi?acc=GSE130969 (accessed on Apr 26, 2020).

41. Khatib, A.-M.; Lahlil, R.; Scamuffa, N.; Akimenko, M.-A.; Ernest, S.; Lomri, A.; Lalou, C.; Seidah, N.G.; Villoutreix, B.O.; Calvo, F.; et al. Zebrafish ProVEGF-C expression, proteolytic processing and inhibitory effect of unprocessed ProVEGF-C during fin regeneration. PLoS ONE 2010, 5, e11438, doi:10.1371/journal.pone.0011438.

42. Siegfried, G.; Basak, A.; Prichett-Pejic, W.; Scamuffa, N.; Ma, L.; Benjannet, S.; Veinot, J.P.; Calvo, F.; Seidah, N.; Khatib, A.-M. Regulation of the stepwise proteolytic cleavage and secretion of PDGF-B by the proprotein convertases. Oncogene 2005, 24, 6925-6935, doi:10.1038/sj.onc.1208838.

43. Zbidi, H.; Jardin, I.; Woodard, G.E.; Lopez, J.J.; Berna-Erro, A.; Salido, G.M.; Rosado, J.A. STIM1 and STIM2 Are Located in the Acidic Ca2+ Stores and Associates with Orai1 upon Depletion of the Acidic Stores in Human Platelets. J Biol Chem 2011, 286, 12257-12270, doi:10.1074/jbc.M110.190694. 
528

529

530

531

532

533

534

535
44. Sanchez-Collado, J.; Lopez, J.J.; Jardin, I.; Camello, P.J.; Falcon, D.; Regodon, S.; Salido, G.M.; Smani, T.; Rosado, J.A. Adenylyl Cyclase Type 8 Overexpression Impairs Phosphorylation-Dependent Orai1 Inactivation and Promotes Migration in MDA-MB-231 Breast Cancer Cells. Cancers (Basel) 2019, 11, doi:10.3390/cancers11111624.

45. Villoutreix, B.O.; Khatib, A.-M.; Cheng, Y.; Miteva, M.A.; Maréchal, X.; Vidal, J.; Reboud-Ravaux, M. Blockade of the malignant phenotype by $\beta$-subunit selective noncovalent inhibition of immuno- and constitutive proteasomes. Oncotarget 2017, 8, 10437-10449, doi:10.18632/oncotarget.14428. 